\title{
Response to the Letter: Impact of SARS-CoV-2 Infection on Patients Suffering from Liver Injury
}

\author{
Olympia E. Anastasiou ${ }^{a}$ Christian M. Lange ${ }^{b}$ \\ anstitute for Virology, University Hospital Essen, University of Duisburg-Essen, Essen, Germany; bepartment of \\ Gastroenterology and Hepatology, University Hospital Essen, Essen, Germany
}

\section{Dear Editor,}

We thank Dr. Vyas for the interest in our work and the editorial team of Digestive Diseases for the opportunity to respond to the comments in the above-mentioned letter [1]. Our study focused on the temporal pattern of liver injury and SARS-CoV-2 detection in the respiratory tract and patient outcome in conjunction with the degree of liver injury [2]. Thus, we were somewhat surprised with the following statement: "...observation of the present study that the fate of COVID-19 (is) majorly dependent of comorbidity and age of patients." Our study did not focus on these issues (age and comorbidities were evaluated as potential confounding factors) and is thus not the best source to draw such conclusions.

An important critique point was: "The severity due to SARS-CoV-2 infection in majority of cases is directly proportional to blood oxygen saturation levels $\left(\mathrm{SpO}_{2}\right)$." The cited article, however, does not support this claim as it comments on a different issue, namely, the target oxygen saturation in COVID-19 therapy [3]. Lung injury is relevant to COVID-19 outcome and this aspect was not highlighted in our study. This limitation should be addressed in future studies. It should be noted that the degree of lung injury in our cohort varied greatly ranging from patients without any need for oxygen treatment to patients requiring extracorporeal membrane oxygenation; $\mathrm{SpO}_{2}$ alone would not be a reliable marker for lung injury.

$\begin{aligned} & \text { karger@karger.com } \\ & \text { www.karger.com/ddi }\end{aligned}$
Karger $V^{\prime / 6}$

Another critique point was the classification of patients, which was performed based on ALT and bilirubin and not age. Since our study focused on liver injury, we find it appropriate to form patient groups according to it. The study was also criticized for not including non-SARSCoV-2 acute liver failure (ALF) patients as a control group and not discussing the outcome of ALF patients due to other common etiologies such as viral hepatitis. Data on ALF mortality have been previously published, including data from our hospital, which put the ALF mortality (irrespective of liver transplantation) at $18 \%$ in general [4] and at about $10 \%$ for cases with autoimmune hepatitis or hepatitis $B$ infection in particular $[5,6]$. Our study focused on SARS-CoV-2 infected patients. In contrast with diseases such as hepatitis $\mathrm{B}$, where the primary target of the disease is the liver, liver injury in SARS$\mathrm{CoV}-2$ is only a (secondary) aspect of the disease. Thus, we do not think that a comparison between SARS-CoV-2 infected patients and the afore-mentioned groups is meaningful.

\section{Conflict of Interest Statement}

O.E.A. has received a research grant from Hexal, unrelated to the submitted work. C.M.L. has received speaker fees from AbbVie, Gilead, MSD, and Norgine and travel support from AbbVie and Gilead, all unrelated to the submitted work. 


\section{References}

1 Vyas AK, Singh A. Impact of SARS-CoV-2 infection on patients suffering from liver injury. Dig Dis. 2020 Oct 9.

2 Anastasiou OE, Korth J, Herbstreit F, Witzke $\mathrm{O}$, Lange $\mathrm{CM}$. Mild vs severe liver injury in SARS-CoV-2 infection. Dig Dis. 2020 Aug 10; $1-6$
3 Shenoy N, Luchtel R, Gulani P. Considerations for target oxygen saturation in $\mathrm{CO}$ VID-19 patients: are we under-shooting? BMC Med. 2020 Aug 19;18(1):260.

4 Anastasiou OE, Kälsch J, Hakmouni M, Kucukoglu O, Heider D, Korth J, et al. Low transferrin and high ferritin concentrations are associated with worse outcome in acute liver failure. Liver Int. 2017 Jul;37(7):103241.
5 Anastasiou OE, Dogan-Cavus B, Kucukoglu O, Baba H, Kahraman A, Gerken G, et al. Corticosteroid therapy improves the outcome of autoimmune hepatitis-induced acute liver failure. Digestion. 2018;98(2):104-11.

6 Anastasiou OE, Widera M, Westhaus S, Timmer L, Korth J, Gerken G, et al. Clinical outcome and viral genome variability of hepatitis $B$ virus-induced acute liver failure. Hepatology. 2019 Mar;69(3):993-1003. 